\title{
OCCURRENCE OF PLACENTAL SCARS IN THE UTERUS OF THE AFRICAN ELEPHANT (LOXODONTA AFRICANA)
}

\author{
R. M. LAWS \\ Department of Zoology, Cambridge \\ (Received 9th February 1967)
}

\begin{abstract}
Summary. Placental scars were recorded in the uteri of forty-four non-pregnant mature elephants. Some 159 scars were observed averaging $3 \cdot 6 /$ female (range 1 to 9 ). They were almost equally distributed between the right and left cornua, and the distribution of implantation sites is illustrated. The relation between estimated ages of the elephants and the number of placental scars they show indicates a mean calving interval of about 4 years but there is evidence that the calving interval has increased in recent years.
\end{abstract}

\section{INTRODUCTION}

The elephant placenta is vasochorial, rather than, in the strict sense, endotheliochorial (Amoroso \& Perry, 1965) and as Perry (1953) remarks in an earlier paper: "It is clear ... that a considerable amount of maternal tissue comes away with placental tissue of foetal origin when the after-birth is shed". This has been observed in recent studies in East Africa. The placental band may be up to $21 \mathrm{~cm}$ wide near term.

Among 300 elephants recently cropped in the Tsavo National Park, Kenya, to provide basic data for a long-term research programme were ninety-three adult females, of which twenty-five were pregnant and sixty-eight non-pregnant. Scars from previous implantations have been useful in studies of other mammals, especially rodents and carnivores, and were, therefore, looked for in elephant uteri.

\section{MATERIAL AND METHODS}

Initially an attempt was made to record placental scars in the uteri of all mature females but, owing to the distension of the cornua and oedema of the endometrium during pregnancy, few were seen in pregnant females and it was concluded that the probability of missing scars was high. The investigation was, therefore, confined to non-pregnant mature females.

Uteri were slit from the cervix to near the uterotubal junction, as indicated diagrammatically in Text-fig. 1. The endometrium was carefully searched, visually, for evidence of scars.

Scars, which clearly represented the sites of previous implantations, were 
found in the uteri of all non-pregnant mature females examined $(n=44)$. The frequency of occurrence ranged from 1 to 9 and several objective age classes could be distinguished. These were recorded as 'very recent', the uterus still partly distended and oedematous and each patch of white scar tissue at least $5 \mathrm{~mm}$ broad; 'recent', the thickness of the scar band not more than about $2 \mathrm{~mm}$; 'moderately old', little scar tissue can be seen (less than $1 \mathrm{~mm}$ broad) but there is a conspicuous transverse groove in the endometrium; 'old', very little or no scar tissue can be seen macroscopically and the transverse groove is inconspicuous; scar tissue is seen in macroscopic and microscopic sections. Nearly all females that were lactating had at least one 'recent' or 'very recent' scar. The active zonary placenta is usually divided at one or more points into two or three separate lobes and consequently the scars produced are often discontinuous. In some cases identification of 'old' scars was dubious and they were only recorded when it was clear that there was some scar tissue, however tenuous, present. This can often be felt as a harder ridge of scar tissue which might not be immediately visible on the surface of the endometrium. Doubtful scars were collected for laboratory examination. The sites and classes of scars were entered in the field on a diagram of the uterus for seventeen females with seventy-three scars.

\section{RESULTS}

Some 159 placental scars were observed, a mean incidence of $3 \cdot 6 /$ female, each corresponding to a pregnancy that progressed to near term or to full term. The scars extend other information on elephant reproduction in several ways: (1) They demonstrate the bilateral function of the uterine horns and the location of implantation sites in the uterus. (2) They provide an independent check on the mean age at puberty or first conception. (3) They give information on the duration of the calving interval in elephant females and some indication of individual variation. (4) Information about the number of calves a cow has produced is helpful in analysing the structure of, and relationships within, the family units (Laws \& Parker, 1967).

The scars in the two horns of the uterus were recorded separately; there were eighty-eight in the right cornu (with $95 \%$ confidence intervals, $55.0 \pm$ $7.9 \%$ ) and seventy-two in the left cornu $(45.0 \pm 7.9 \%)$. The difference is not significant and the two cornua are equally active.

The observations give a good quantitative picture of the distribution of the implantation sites in the uterus (though uncorrected for the muscle contraction which persists for a short time after death). The records have been transferred to a summary diagram (Text-fig. 1) in which each transverse line marks a previous implantation site. The usual position is about two-thirds along the cornu from the tubal end, although some embryos had implanted much nearer the tube. In general the recent sites in young mature animals approximate to the mean location; when there are several scars they are usually spaced at 1 to $2 \mathrm{~cm}$ apart about this position; in old animals the oldest scars usually approximate to this position and the newer scars tend to be peripheral. The most marginal scars are found in old females; the mean age of five with the most peripheral scars $(46.2$ years) was significantly greater than that of the remaining 
twelve $(27.0$ years $)(t=6.322, P<0.001)$. Apparently the position of the implantation site is influenced by the location of previous implantation sites, even those represented by scars formed many years before.

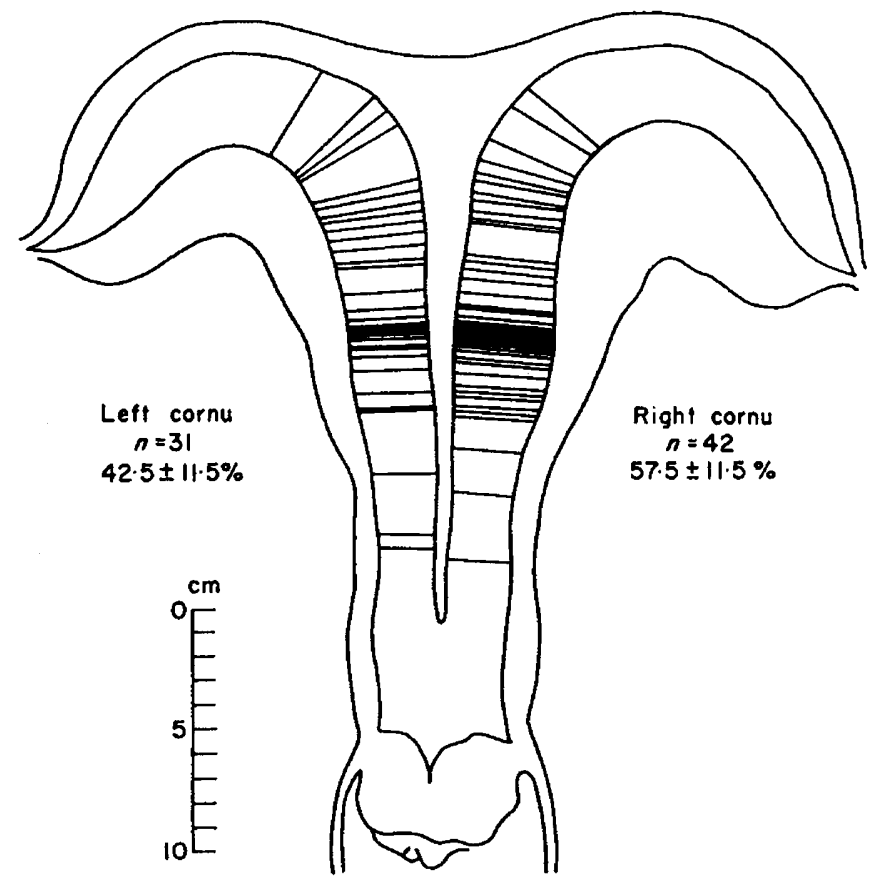

Text-FIG. 1. Summarized distribution of seventy-three placental scars in the uterus. The thicker bands are due to the crowding and overlap of lines representing individual scars.

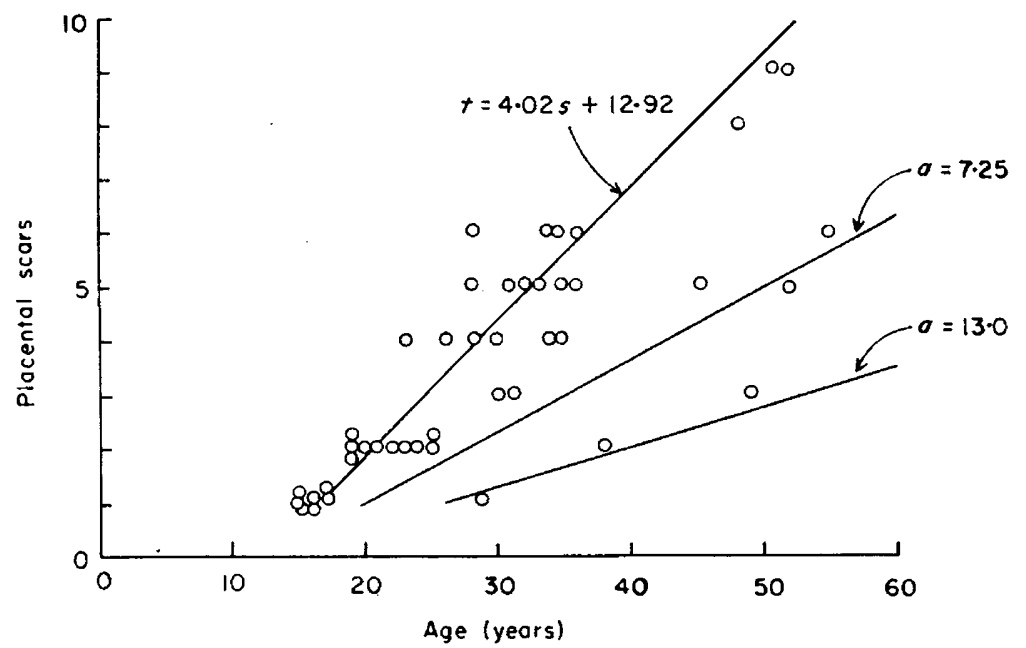

TExT-FIG. 2. Relation between number of placental scars and age.

The ages of these females have been determined according to published criteria (Laws, 1966) and in Text-fig. 2 the frequency of scars is plotted against age. Evidence derived from examination of the ovaries indicates that the mean 
age at puberty in this population is 12 to 13 years, with a range of 10 to 18 years (Laws \& Parker, 1967). The regression of number of scars $(s)$ on age $(t)$ is given by:

$$
t=4.08 s+14.99 \text { years }
$$

The slope $(a)$ is an estimate of the mean calving interval ( 4.08 years) and when $s=1, t=19 \cdot 08$, suggesting that the first pregnancy was initiated on average at 15 to 17 years (since the gestation period is 22 months and lactation anoestrus lasts at least 2 years). However, this estimate is heavily influenced by the data for several anomalous females. Five out of six females with relatively low scar counts (Text-fig. 2) showed anomalies probably related to their apparently lowered reproductive success. Two had large cysts on the bursa ovarii (aged 29 and 52 years); two were blind (aged 38 and 55 years), and one of them ( 55 years) was with two adult bulls, having left or lost her family unit; three (aged 38, 49 and 55 years) had crops of very small corpora lutea in the ovaries. Their total luteal tissue weights were 0.56 to $2.04 \mathrm{~g}$, compared with a range of $9 \cdot 0$ to $17.5 \mathrm{~g}$ shown by normal non-pregnant cycling females.

If these anomalous females are eliminated the regression equation is:

$$
t=4.02 s+12.92 \text { years }
$$

giving an estimate of 4.02 years for the mean calving interval (very similar to the previous one) but for $s=1, t=16.94$ years, suggesting that the first pregnancy began at 13 to 14 years. An interpretation of these six records of low scar counts in terms of late puberty and longer mean calving intervals (7.25 years and 13.0 years) is shown in Text-fig. 2.

Twins (incidence one in twenty-five pregnancies) would produce two scars and this could explain the highest indicated rates (together with precocity). Conversely, 40 years is a long time for a scar to persist in grossly recognizable form in the endometrium and it is possible that some animals give undercounts, either because the scars may cease to be visible in old animals or because a subsequent implantation site lies very close to an earlier one and obscures it. Alternatively, some of the low scar counts may represent females that consistently aborted while the embryo was too small for the placenta to leave a permanent scar.

\section{DISCUSSION}

It may be thought that this picture is unduly influenced by inherent inaccuracies in the method of age determination but the variance in, for instance, body length at age is small. Together with other checks, this gives confidence in the age determination (Laws, 1967; Laws \& Parker, 1967), and suggests that there are large differences between individual calving rates. This has also been borne out by the analysis of the social structure of family units, which, however, is influenced by the combined effects of fertility and calf mortality rates (Laws \& Parker, 1967). The main conclusion to be drawn is that some females may perhaps give birth to as few as three calves in 50 years, others to as many as nine.

For Western Uganda the material collected by Perry (1953) indicated a 
mean calving interval of 3.8 years in the years 1947 to 1950 ; current research on the same populations suggests that the mean calving interval has increased to 8.9 years (Laws \& Parker, 1967). Similarly in Tsavo, the mean calving interval is unlikely to have remained constant for 40 years and the relationship between scar number and age could be expected to be curvilinear. That is, concave or convex upwards, according to whether the fertility rate was decreasing or increasing during that period. Since there is some uncertainty about the permanence of the placental scars over long periods of time, let us restrict ourselves to the group of animals aged up to 36 years (ignoring the anomalous low value at 29 years). There is an indication that the mean calving interval may have increased in recent years, suggesting a lowered fertility. Thus, the difference between the mean ages of 1- and 2-scar groups is 6.7 years. This could be influenced by advancement of the mean age at puberty, but independent evidence from the proportion of mature females in the sample that are pregnant indicates a current mean calving interval of 6.8 years.

\section{ACKNOWLEDGMENTS}

I am indebted to the Kenya National Parks and to Wildlife Services Ltd, especially I. S. G. Parker and A. L. Archer, for their co-operation which made the collection of this material possible. The work was partly financed by the Nuffield Foundation and I am grateful to Professor A. S. Parkes for facilities provided by his Department.

\section{REFERENCES}

Amoroso, E. C. \& Perry, J. S. (1965) The foetal membranes and placenta of the African elephant (Loxodonta africana). Phil. Trans. B, 248, 1.

Laws, R. M. (1966) Age criteria for the African elephant, Loxodonta a. africana. E. Afr. Wildl. F. 4, 1.

LAws, R. M. (1967) Eye lens weight and age in African elephants. E. Afr. Wildl. F. 5. (In press).

LAws, R. M. \& Parker, I. S. C. (1967) Recent studies on elephant populations in East Africa. In Comparative Nutrition of Wild Animals. Ed. M. A. Crawford. Symp. Zool. Soc. Lond. 21. (In press).

Perry, J. S. (1953) The reproduction of the African elephant, Loxodonta africana. Phil. Trans. B, 237, 93. 